\title{
Mechanical Model for Steel Frames with Discretely Connected Precast Concrete Infill Panels with Window Openings
}

\author{
P.A. Teeuwen ${ }^{*, 2}$, C.S. Kleinman ${ }^{1}$ and H.H. Snijder ${ }^{1}$ \\ ${ }^{I}$ Department of Architecture, Building and Planning, Eindhoven University of Technology, The Netherlands; \\ ${ }^{2}$ Witteveen + Bos engineering and Consulting Agency, Deventer, The Netherlands
}

\begin{abstract}
This paper presents a mechanical model for a structure comprising of steel frames with discretely connected precast concrete infill panels having window openings, termed semi-integral infilled frames. The discrete panel-to-frame connections are realized by structural bolts acting under compression. The mechanical model enables analysing a building structure consisting of semi-integral infilled frames by standard structural analysis methods. Input for the model are geometrical and material properties of the frame structure and the structural characteristics of three types of springs representing the frame joints, the panel-to-frame connections and the infill panel respectively.

An overview of some of the research undertaken at Eindhoven University of Technology to study the behaviour of the springs representing the panel-to-frame connections is presented.Tests on individual components of the panel-to-frame connection were performed to establish load-displacement characteristics of the connection. A finite element model has been developed to investigate the structural behaviour of the components 'flanges in bending'combined with 'web in compression' by varying different parameters. The results of the research allow estimating the structural characteristics of the considered discrete panel-to-frame connection for different frame sections.
\end{abstract}

Keywords: Infilled frame, steel, precast concrete, discrete connection, lateral stability.

\section{INTRODUCTION}

The infilled frame is a type of structure that acts by composite action between the infill and its surrounding frame to resist in-plane lateral loads. Structural interaction between the two components produces a composite structure with a complicated behaviour due to the fact that the frame and the infill mutually affect each other. Since the early fifties extensive research has been done into the composite behaviour of infilled frames with masonry and cast-in-place concrete infills $[1,2]$. Although a lot of the investigations were conducted on infilled frames with solid infills, few studies have been conducted on infilled frames with openings. Those studies that were carried out are mainly restricted to masonry infills. It has been demonstrated that the presence of an opening in the infill substantially alters the performance of infilled frames [3-5]. Furthermore, recommendations have been made for suitable opening positions within an infill [6].

The application of precast concrete infill panels created a new area of research in infilled frames [7,8]. These can be classified as semi-integral infilled frames. Discrete panel-toframe connections are required to allow for composite action between the panel and the surrounding frame. It has been demonstrated that discretely connected precast concrete panels with window openings can be successfully used to provide lateral stability to steel frames under static in-plane loading conditions $[9,10]$. This article presents a mechanical model for this type of structure. The basic characteristic of

*Address correspondence to this author at the Witteveen+Bos engineering and consulting agency, Deventer, The Netherlands;

Tel: +31 7652333 28; E-mail: p.a.teeuwen@upcmail.nl mechanical models is that they aim at predicting the overall stiffness and failure loads, also considering all possible failure modes of local failure.

\section{DISCRETE PANEL-TO-FRAME CONNECTION}

Essential parts of the semi-integral infilled frame are the discrete interface connections between the precast concrete panel and the steel frame. Besides facilitating the panel and frame to act compositely when laterally loaded, the connections should contribute to the improvement of the constructability of buildings. Accordingly, the connections should allow the assembly to be performed with a minimum of manpower, enable adoption of manufacturing and site erection tolerances and allow inspection and adjustment in a simple way. This way, a fast erection on site can be achieved. Finally, the connections and their reinforcement detailing shall not adversely influence economic manufacturing of the precast panels and their transport.

The connection between infill and steel frames considered in this paper is realized by structural bolts in pairs on the column and beam in every corner of the steel frame (Figs. 1 and 2). The precast concrete infill panel is confined within the steel frame by these bolts, leaving a small gap between panel and frame along the whole panel circumference. To introduce forces into the panel, steel angles anchored by reinforcement are cast in the concrete at every corner of the panel. High-strength steel caps are applied between the bolts and the steel angles to reduce the contact stresses in the angles by increasing the contact area. The connections are located in the panel corners, and are unable to transfer tensile forces. Therefore, only the bolts in the compression corners are active in a laterally loaded system. 

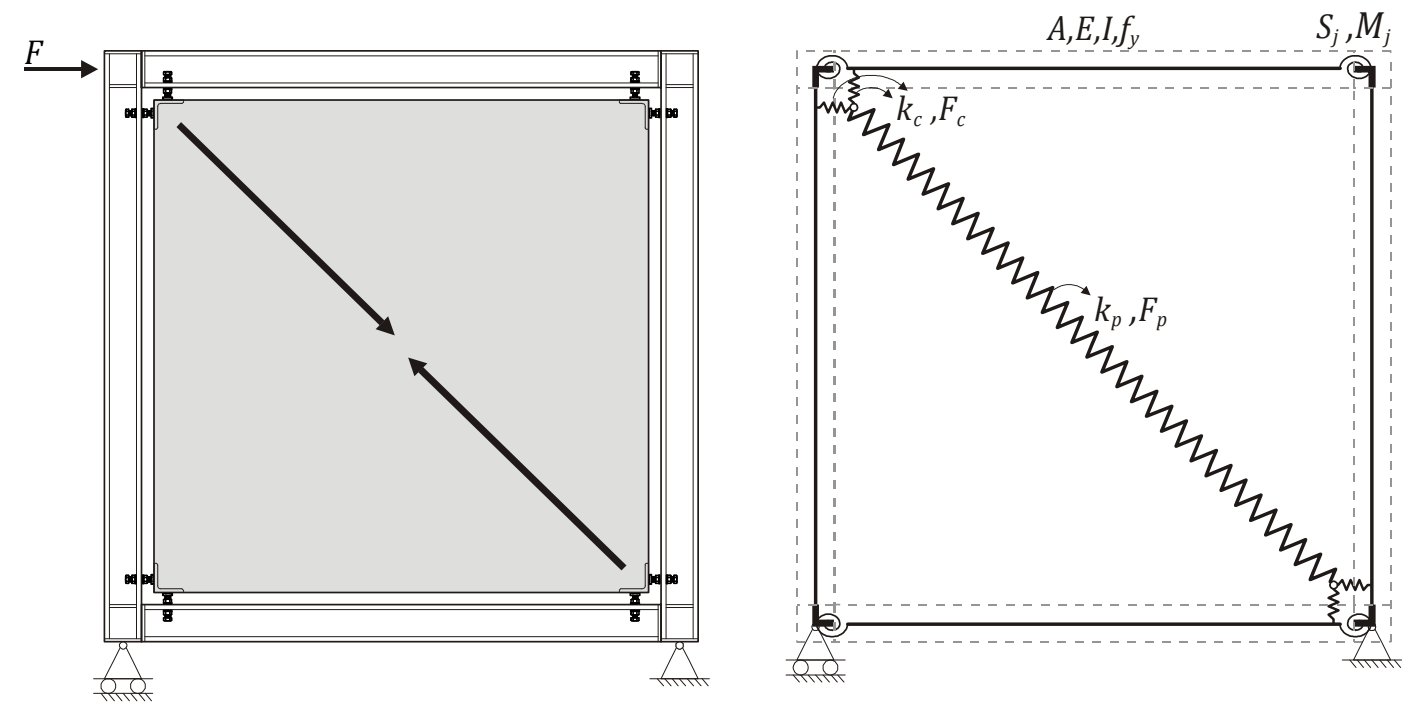

Fig. (1). Semi-integral infilled frame (left) and mechanical model (right).

Consequently, the infill panel has to act as a diagonal under compression which makes the effect of the infill panel similar to the action of a diagonal compression strut bracing the frame.

\section{MECHANICAL MODEL}

A mechanical model is proposed for the semi-integral infilled frame with this type of connection (Fig. 1). The model is based on the concept of the equivalent diagonal strut [11], in which the global action of the panel is represented by a translational spring having stiffness $k_{p}$ and strength $F_{p}$. Frame members are represented by beam elements. The frame joints are represented by rigid offsets to take the depth of the columns and beams into account, and a rotational spring with stiffness $S_{j}$ and resistance $M_{j}$. The discrete panelto-frame connections are represented by translational springs having stiffness $k_{c}$ and strength $F_{c}$.

The proposed model enables analysing a building structure consisting of semi-integral infilled frames by standard structural analysis methods. Input for the model are geometrical and material properties of the frame members and the characteristics of the three types of springs representing the frame joints, the discrete panel-to-frame connections and the infill panel respectively. Research has been carried out to establish load-displacement characteristics of these springs. An overview of some of the research undertaken to study the behaviour of the springs representing the panel-to-frame connections is presented in more detail.

\section{Structural Characteristics of Frame Joints}

For many years, extensive research on bolted and welded beam-to-column joints has been carried out. For example, in the Netherlands research was conducted e.g. by Witteveen et al. [12] and by Stark and Bijlaard [13]. Design rules to determine the structural behaviour of joints in building frames in terms of strength, stiffness and deformation capacity have been incorporated in e.g. Eurocode 3 EN 1993-1-8 [14]. Hence, the (initial) rotational stiffness $\left(S_{j}\right)$ and the resistance $\left(M_{j}\right)$ of the frame joints can be predicted by existing design rules and, therefore, require no further investigation.

\section{Structural Characteristics of Discrete Panel-to-Frame Connections}

The discrete panel-to-frame connection can be partitioned into basic components, analogously to the component method in Eurocode 3 EN 1993-1-8 [14] for the design of joints. The basic idea of this method is to consider a joint as an assembly of individual simple components. Consequently, the structural characteristics of the connection depend on the properties of its basic components. The method allows accommodating different joint typologies under the same basic principles.

The identified basic panel-to-frame connection components include the column/beam web in compression, the column/beam flanges in bending, bolts in compression and a plate in compression. These components act in series. Consequently, the overall connection behaviour can be represented by considering the component springs shown in Fig. (2). The connection stiffness $\left(k_{c}\right)$ can be determined from the stiffness of its basic components, each represented by its elastic stiffness coefficient $\left(k_{c i}\right)$. The connection strength $\left(F_{c}\right)$ is dictated by the resistance of its critical basic component $\left(F_{c i}\right)$.

The infilled frame structure is intended to be designed such, that the strength of the structure is governed by the panel-to-frame connections. Accordingly, the overall strength of the structure is governed by a failure mechanism which can be aimed for in advance. In this case the connections will be designed for a 'bolt failure' mechanism $\left(F_{c 3}\right)$. The preferred failure mode is shearing of the bolt through the nut. Failure of the bolts will not directly result in failure of the structure, as force transmission will still occur in the loaded corners of the frame by contact pressure between frame and panel (fail safe concept). Moreover, bolts can rather easily be replaced. Therefore, the strength of the other three components must exceed the strength of the bolt component, where in this particular case strength is defined as the onset of yielding. In other words, no plastic deformation is allowed in the other three components at the moment of bolt failure. 

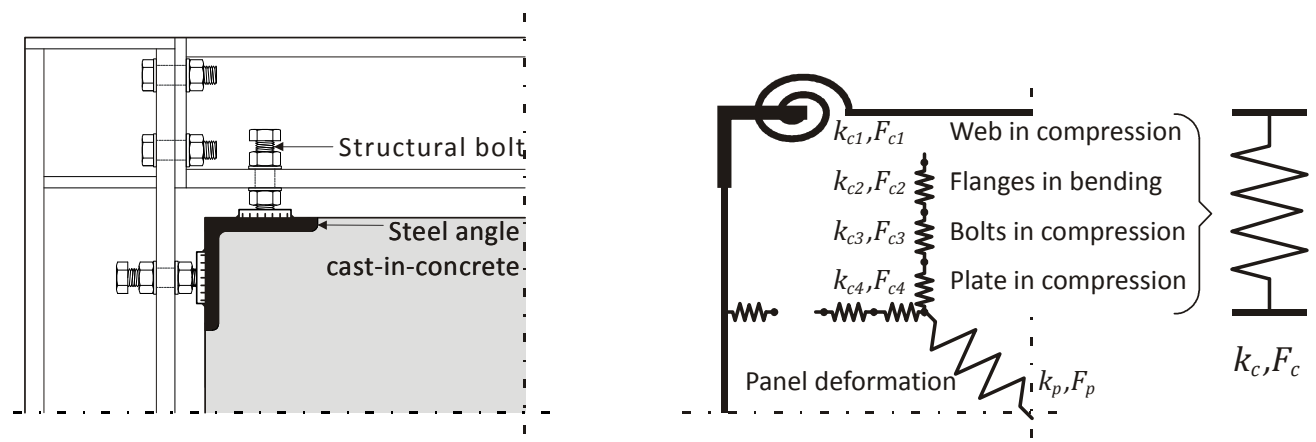

Fig. (2). Discrete panel-to-frame connection (left) and mechanical model (right).

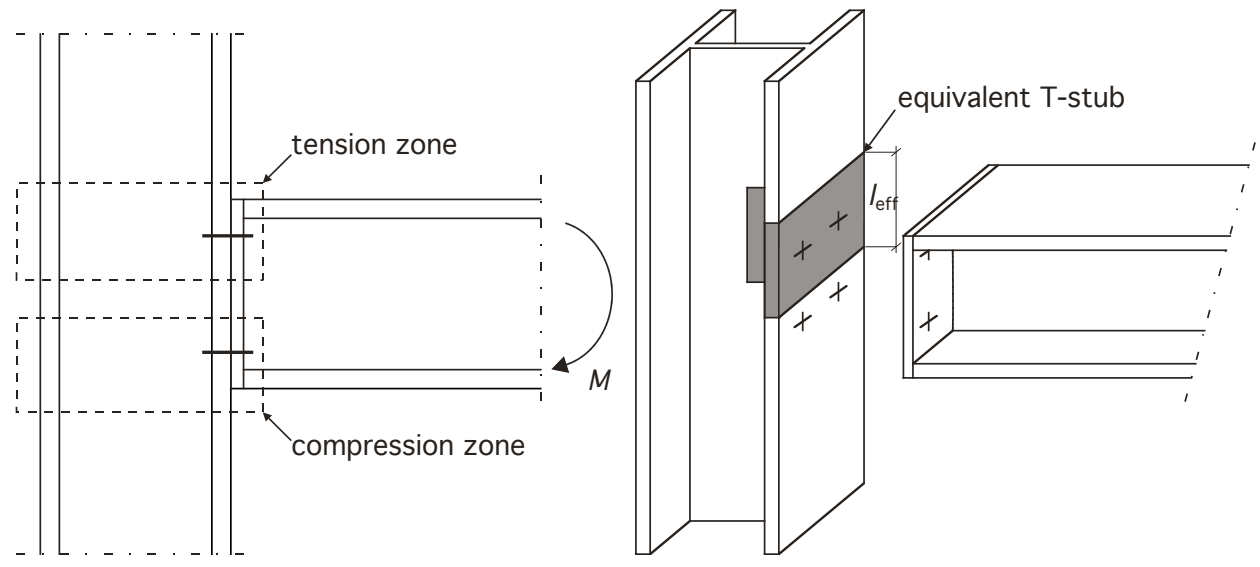

Fig. (3). Tension and compression zone in bolted end plate connection (left) and equivalent T-stub representation of the tension zone (right).

For the serial component spring of the panel-to-frame connection, the following equations with respect to the stiffness $\left(k_{c}\right)$ and strength $\left(F_{c}\right)$ hold:

$$
\begin{aligned}
& k_{c}=\left[\frac{1}{k_{c 1}}+\frac{1}{k_{c 2}}+\frac{1}{k_{c 3}}+\frac{1}{k_{c 4}}\right]^{-1} \\
& F_{c}=\min \left[F_{c 1}, F_{c 2}, F_{c 3}, F_{c 4}\right]
\end{aligned}
$$

Experiments were performed on the components of the panel-to-frame connection to establish the stiffness and failure load of the several mechanisms.

\section{Web in Compression}

A web subject to transverse compression applied directly through the flange may fail in one of the following three ways. The most likely form of failure is web crushing. In this case, the local stresses developed in the web exceed the yield strength of the steel. For slender webs, it is possible that failure occurs by buckling of the web or by some form of local instability known as web crippling. Eurocode 3 EN 1993-1-5 [15] covers each of the three failure modes (crushing, buckling, crippling) for fabricated or rolled beam sections.

However, when the load is applied to the web via flange bending caused by the applied forces by the two bolts, web crushing, web crippling and web buckling are not likely to occur while flange yielding governs the strength. Accordingly, only the stiffness of the web in compression is of interest. While flange and web geometry of wide flange beams are inseparable, tests and analyses were combined with the flange bending component.

\section{Flanges in Bending}

The flange bending component in the panel-to-frame connection shows similarity to flanges in bending at the tension side of columns in bolted beam-to-column connections. Yet, here the flanges are subjected to transverse tension instead of compression. Analytical models for the determination of the flange capacity were developed by Zoetemeijer [16]. The results of this work suggest that an equivalent $\mathrm{T}$ stub with an effective length $\left(l_{\text {eff }}\right)$ can be used to model the tension region of the column flange (Fig. 3). To define the effective length, the complex pattern of yield lines that occurs around the bolt(s) is converted into a simple equivalent T-stub. Subsequently, simplified equations based on simple bending theory are used for calculating the strength and elastic stiffness of the T-stub assembly.

In these models a prying action is assumed to develop at the end of the flange. Prying is a phenomenon in which additional tensile forces are induced in the bolts due to deformation of the connection near the bolt. The prying action is implicit in the expression for the calculation of the effective length. However, due to absence of this prying action, these expressions are inaccurate for the prediction of the structural characteristics of the flange bending component in the panelto-frame connection. Besides, the full elastic-plastic response is not covered by these expressions. Therefore, in orderto determine the stiffness and strength of flanges of HEsections in bending, experiments and numerical research have been carried out.

HE200B sections with welded end plates were subject to transverse compressive loading, introduced by $10.9 \mathrm{M} 24$ 

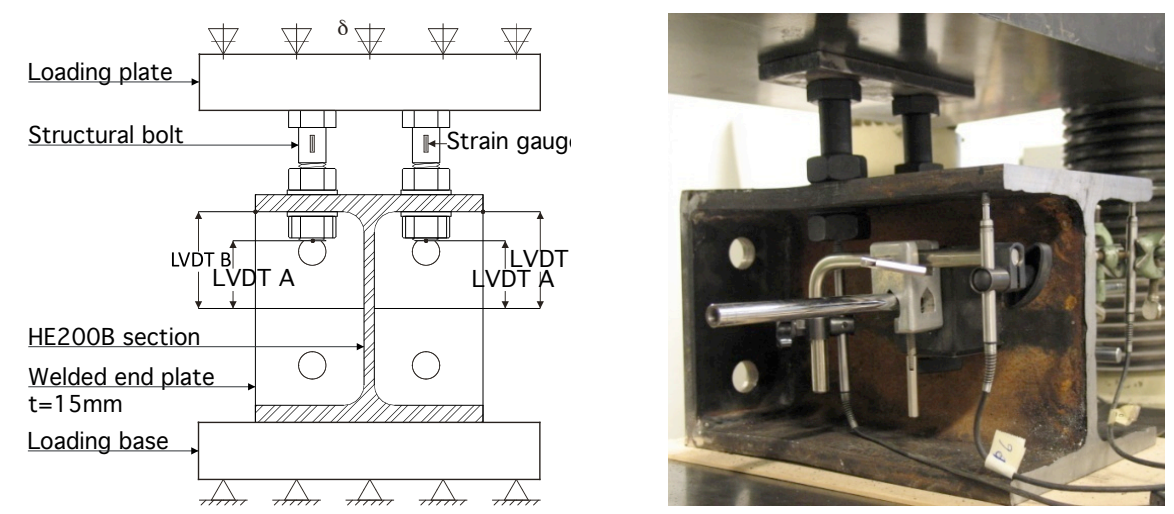

Fig. (4). Overview of test setup for component 'flanges in bending with web in compression'.

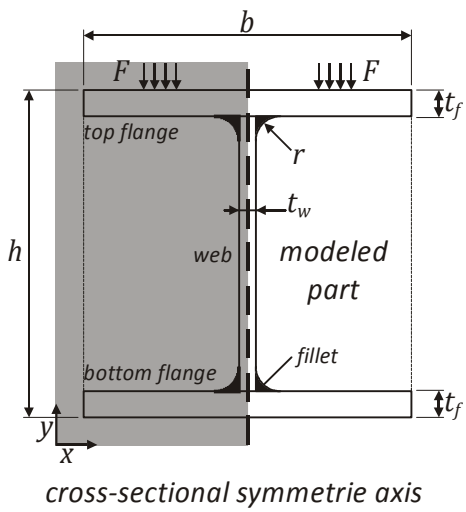

a)

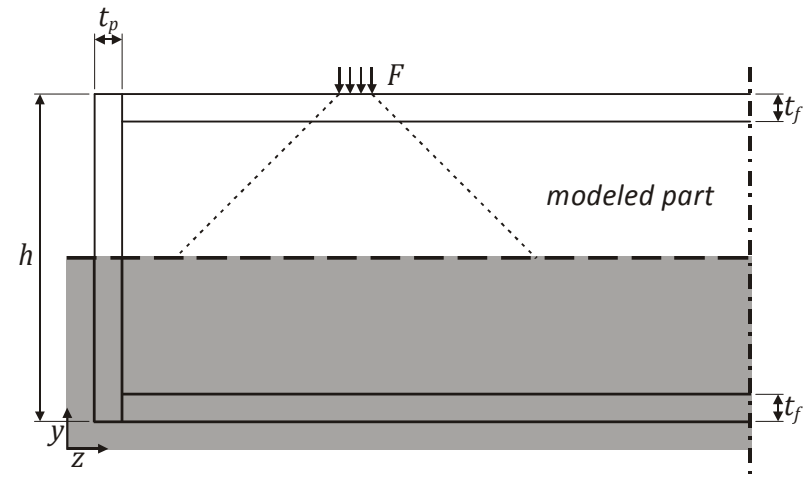

b)

Fig. (5). Model design- cross-section (a) and side view(b).

bolts on the flanges, in a compression test setup. The load application was displacement controlled at $0.10 \mathrm{~mm} / \mathrm{min}$ in the elastic range and at $0.20 \mathrm{~mm} / \mathrm{min}$ in the plastic range. LVDTs were used to measure displacements under the bolts and under the end of the outside of the flanges. Three strain gauges with lengths of $10 \mathrm{~mm}$, equally divided around the shank of the bolt, were used to measure strains at the bolt surface. These measurements allowed determination of the load distribution over the two bolts. Fig. (4). gives an overview of the test setup.

Fig. (6) presents the load-displacement diagrams of two tests with HE200B sections subject to transverse compression. The shown displacement is the maximum measured under the two bolts (LVDTs A) and plotted against the load in the bolt. The load-deformation curve can be approximated by a linear elastic branch followed by a nearly unlimited second plastic branch. The plastic behaviour results from yielding of the flanges, and represents a ductile failure mechanism. At the end of the branches, the tests were stopped.

The foregoing experimental research was supplemented by finite element (FE) analyses. The finite element program used was ANSYS, release 10.0. A half model was created by taking advantage of symmetry. Besides, to reduce the number of elements, degrees of freedom and so the calculation time, only the upper half part of the section was modelled. Deformations of the lower half part are negligible in comparison with deformations of the upper half part because of the distribution of the stresses with the depth of the section
(Fig. 5). Solid elements were used to model the geometry of the cross-section to get a very accurate geometry. The finite element model consisted of 8-node (SOLID 45) and 20-node (SOLID 95) structural solids. A solid 95 is a higher order version of SOLID 45 which can tolerate irregular shapes without much loss of accuracy. Four elements through the thickness were applied to model the flange and the web. For the parts of the flange near the bolt hole, a fine mesh was used because large stress gradients are expected at these locations. Parts further away had of a courser mesh (Fig. 6). Non-linear material characteristics and geometrical nonlinearity were taken into account. Tensile tests on coupons made out of the flanges of the HE200B section were performed to determine the actual material properties of the testspecimens.

Several boundary conditions were applied to the FE model. The bottom of the model was fixed along the y-axis, uy $=0$. For nodes at the cross-sectional symmetry axis symmetry boundary conditions were applied, thus $u x=\varphi y=\varphi z$ $=0$. Two types of load applications were applied alternately to the model. The first one modelled the force applied to the flange by a bolt as pressure uniformly distributed over the area of the washer. This loading condition allows free bending of the flange without a clamping moment of the bolt to the flange occurring. The second load type modelled a prescribed displacement over the area of the washer along the yaxis, which represents a full clamping moment at the bolt.

Fig. (6) shows the experimentally found loaddeformation response together with the numerical simula- 

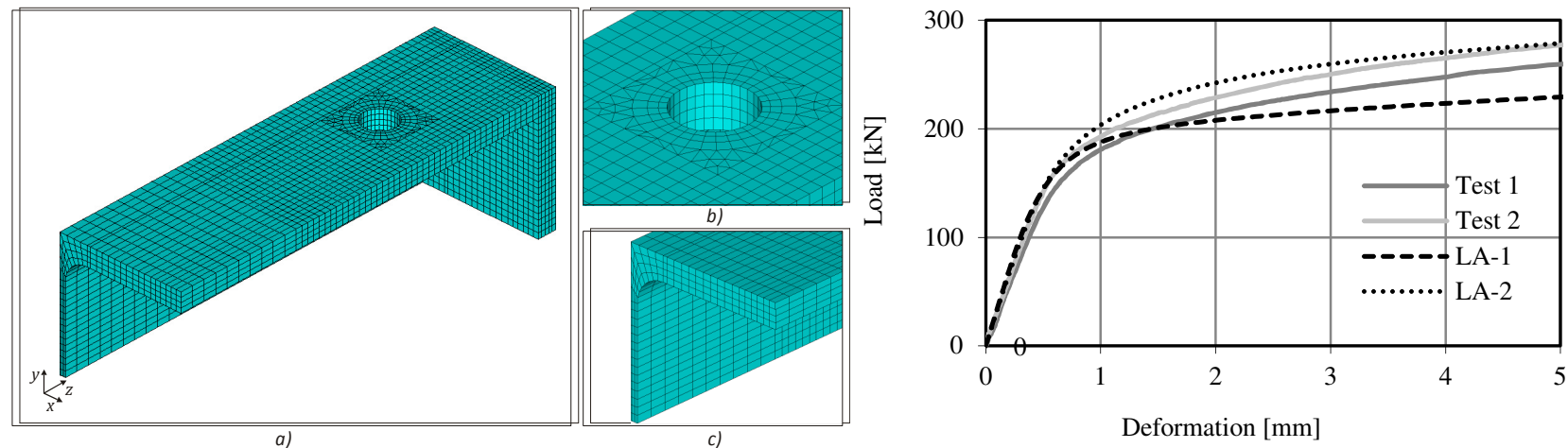

Fig. (6). Finite element model (left) and load-deformation graphs (right) of HE200B-section subject to transverse compression introduced indirectly through the flanges.
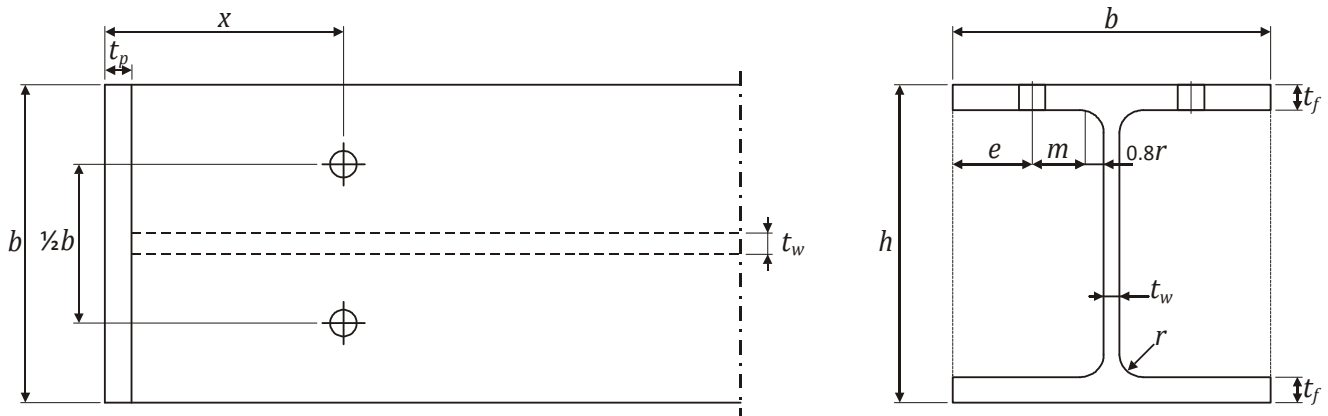

Fig. (7). Illustration of investigated geometrical parameter $\mathrm{x}$ (left) and sectional properties (right).

tions. Both simulations show good agreement in the elastic range and provide an accurate, approximately identical prediction of the linear elastic stiffness. The finite element model with the load applied as a prescribed displacement (LA-2) shows a slight overestimation of the strength. The finite element model with the load applied as a pressure uniformly distributed over the diameter of the washer (LA-1), on the other hand, provides an accurate prediction of the onset of yielding. However, the model gives a conservative prediction of the plastic stiffness. The real behaviour seems to be in between the two simulations. Seeing that the experimental branches tend to fit the graph representing the full clamping moment by increasing deformation, it seems that the influence of the clamping moment by the bolt to the flange increases with increasing flange deformation. Nevertheless, the finite element model with the load applied as a pressure uniformly distributed over the diameter of the washer (LA-1) provides a safe prediction of the real behaviour. Besides, the plastic stiffness is of minor importance for design purposes, taking into account that the desired failure mode of the connection is a bolt failure mechanism, allowing no plastic deformation in the other components.

The validated finite element model (LA-1) allowed to perform a parameter study carried out to find the strength and stiffness characteristics of European rolled HEA- and HEB-sections, subject to transverse compression introduced indirectly through the flanges. The primary parameter that dominates the structural response is the position of the bolts on the flanges Fig. (7). To achieve relatively high strength and stiffness, the bolt distance to the web is taken as small as possible, considering requirements for minimal pitch and end distances. A distance of $1 / 2 \mathrm{~b}$ between the bolts showed to be a practical dimension that meets these requirements. Accordingly, the investigated parameter was the distance of the bolt with respect to the front of the end plate $(\mathrm{x})$. The thickness of the endplate $\left(t_{p}\right)$ was kept equal to the flange thickness $\left(t_{f}\right)$ of the section considered.

The distance $\mathrm{x}$ is related to the section width $\mathrm{b}$ by the non-dimensional parameter $\zeta$ as follows:

$\zeta=x / b$

Numerical simulations were carried out for $\zeta=1 / 4,3 / 8,1 / 2$ and $5 / 8$. Further increase of the factor $\zeta$ did not significantly influence the behaviour. The sections considered are European rolled HEA- and HEB-sections with heights ranging from 200 to $400 \mathrm{~mm}$, as these heights are most common in the area of application of the semi-integral infilled frame.

Fig. (8) presents the typical load-deformation response for HE300A and HE300B sections in S355, subject to transverse compression for $\zeta=1 / 4,3 / 8,1 / 2$ and $5 / 8$ respectively. Based on these graphs, the linear elastic stiffness and design strength were derived. For this purpose, several methods are available. An overview of approaches given in literature can be found in a publication of Steenhuis et al. [17], which deals with the derivation of the strength, stiffness and rotation capacity of steel and composite joints. In this publication, five different approaches are discussed. In all approaches, the elastic stiffness is simply taken as the initial stiffness. Yet, for determination of the strength, different approaches are applied. In two of the approaches, the strength is determined by drawing a line through the part of the test curve with the post-yielding stiffness. Subsequently, the strength is taken at the intersection with the vertical axis 

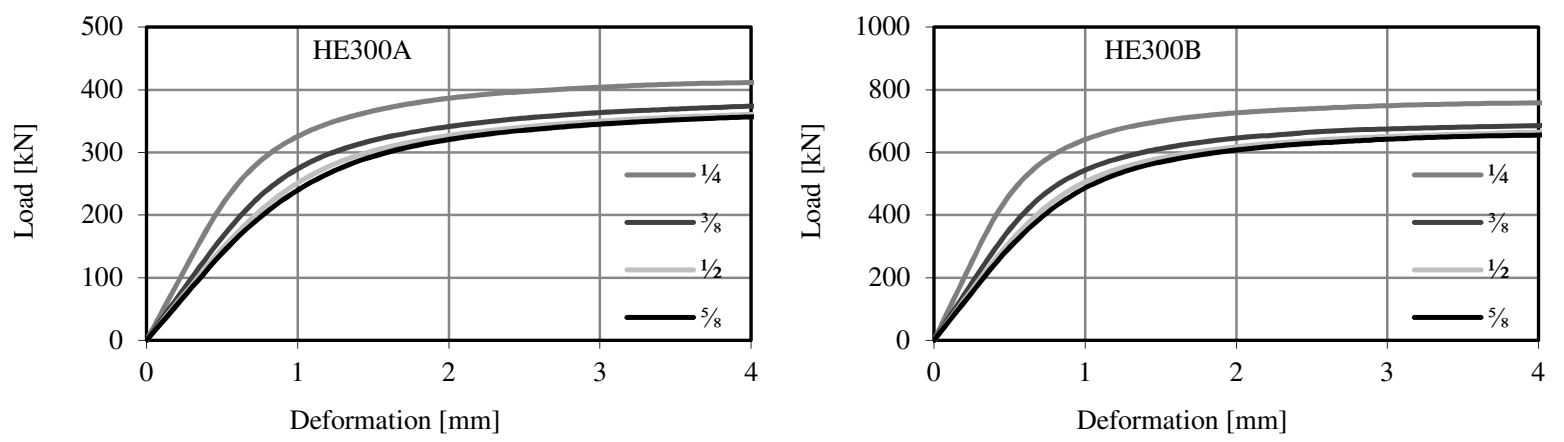

Fig. (8). Load-deformation response of HE300A (left) and HE300B (right) sections in S355, subject to transversecompression for $\zeta=1 / 4,3 / 8$, $1 / 2$ and $5 / 8$

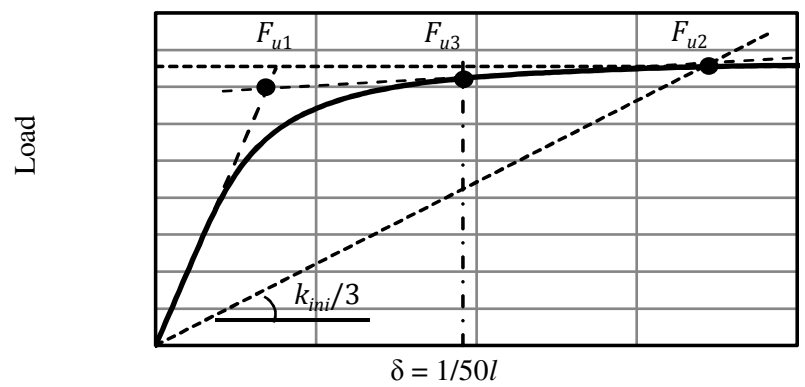

Deformation

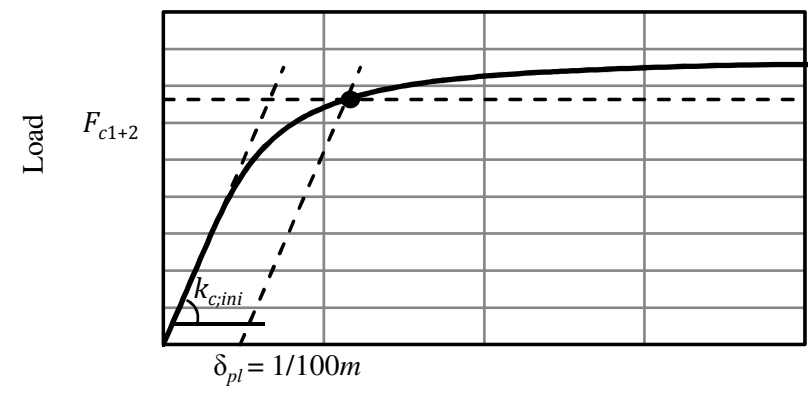

Deformation

Fig. (9). Derivation of $F_{u}$ according to existing approaches (left) and defined approach for derivation of $F_{c_{1+2}}$ (right).

or with the line of the initial stiffness respectively. In a different approach, the strength is chosen as 0.9 times the ultimate strength (or peak load). Finally, two approaches are discussed which are based on a secant stiffness, taken as one third of the initial stiffness. Accordingly, the intersection of the secant stiffness with the test curve defines the strength.

However, the approaches discussed above are not suited for this study. As an example, in Figure 9 a load-deformation curve is shown. An ultimate strength or peak load is not present in this load-deformation curve but nevertheless a strength value needs to be evaluated on the basis of this curve. There are several possibilities to do this:

- Drawing a line through the post-yielding stiffness of the curve seems to result in a rather arbitrarily strength (Fig. 9: $\mathrm{F}_{\mathrm{u} 1}$ ), as there is no obvious linear post-yielding stiffness.

- Taking the secant stiffness as one third of the initial stiffness, and then taking the intersection with the test curve gives extensive plastic deformation (Fig. 9: $\mathrm{F}_{\mathrm{u} 2}$ ). This approach will not be selected as the design of the semiintegral infilled frame is based on bolt failure and plastic deformation of other components is not admitted.

- Another approach, to be found in the former Dutch code (TGB-staal, 1972), consists of a deformation criterion. According to this criterion, the load that gives a deformation of 1/50 times the span (where for cantilevers twice the span is taken) can be considered as the ultimate strength. However, this approach gives considerable plastic deformation as well (Fig. 9: $F_{\mathrm{u} 3}$ ) and is therefore unsuitable.
Therefore, a new approach is defined here with an allowed plastic deformation as deformation criterion. Because allowing no plastic deformation at all results in a very conservative model strength, a rather arbitrary value of $\delta_{p l}=$ $1 / 100 m$ is defined as the allowed plastic deformation (for $m$, see Fig. 7). Subsequently, the model strength is determined by drawing a line with the linear elastic stiffness through a deformation of $\delta_{p l}$, where the linear elastic stiffness of the combined component $\left(k_{c l+2}\right)$ is simply taken as the initial stiffness $\left(k_{c ; i n i}\right)$. The design strength of the combined component $\left(F_{c l+2}\right)$ is then taken at the intersection with the simulated curve (Fig. 9).

An overview of the derived strength and stiffness characteristics for steel S355 is provided in Table $\mathbf{1}$ and in Table $\mathbf{2}$ for European rolled HEA and HEB-sections respectively. It was found that there exists a constant ratio of 0.7 between the strengths of the considered sections in S235 and S355. Accordingly, the design strength of the other sections in S235 can be found by multiplying the strength of the section in S355 with a factor equal to 0.7 .

The strength of a flange $\left(F_{c l+2}\right)$ is influenced by axial stresses $\left(\sigma_{c o m ; E d}\right)$ in the member resulting from axial force or bending moment. Therefore, a reduction of the strength because of possible local buckling has to be contemplated. According to e.g. ENV 1993-1-1 Annex J, the possible reduction of the moment resistance of the column flange should be allowed for when the maximum longitudinal compressive stress $\sigma_{\text {com;Ed }}$ exceeds $180 \mathrm{~N} / \mathrm{mm}^{2}$ by multiplying the flange strength by a reduction factor $k_{f c}$ (Zoetemeijer, 1975):

$k_{f c}=\frac{2 f_{y ; f c}-180-\sigma_{c o m ; E d}}{2 f_{y ; f c}-360}$ 
Table 1. Characteristics for European Rolled HEA-Sections in S355 Subject to Transverse Compression

\begin{tabular}{|c|c|c|c|c|c|c|c|c|}
\hline Section type & \multicolumn{2}{|l|}{$\zeta=1 / 4$} & \multicolumn{2}{|l|}{$\zeta=3 / 8$} & \multicolumn{2}{|l|}{$\zeta=1 / 2$} & \multicolumn{2}{|l|}{$\zeta=5 / 8$} \\
\hline HE220A & $4.40 \mathrm{E}+5$ & $2.38 \mathrm{E}+5$ & $3.13 \mathrm{E}+5$ & $2.06 \mathrm{E}+5$ & $2.73 \mathrm{E}+5$ & $1.95 \mathrm{E}+5$ & $2.57 \mathrm{E}+5$ & $1.90 \mathrm{E}+5$ \\
\hline HE240A & $4.69 \mathrm{E}+5$ & $2.77 \mathrm{E}+5$ & $3.39 \mathrm{E}+5$ & $2.43 \mathrm{E}+5$ & $2.98 \mathrm{E}+5$ & $2.32 \mathrm{E}+5$ & $2.81 \mathrm{E}+5$ & $2.26 \mathrm{E}+5$ \\
\hline HE280A & $4.14 \mathrm{E}+5$ & $3.07 \mathrm{E}+5$ & $3.06 \mathrm{E}+5$ & $2.73 \mathrm{E}+5$ & $2.71 \mathrm{E}+5$ & $2.62 \mathrm{E}+5$ & $2.56 \mathrm{E}+5$ & $2.56 \mathrm{E}+5$ \\
\hline HE300A & $4.46 \mathrm{E}+5$ & $3.52 \mathrm{E}+5$ & $3.32 \mathrm{E}+5$ & $3.15 \mathrm{E}+5$ & $2.95 \mathrm{E}+5$ & $3.03 \mathrm{E}+5$ & $2.80 \mathrm{E}+5$ & $2.97 \mathrm{E}+5$ \\
\hline HE320A & $5.81 \mathrm{E}+5$ & $4.35 \mathrm{E}+5$ & $4.30 \mathrm{E}+5$ & $3.88 \mathrm{E}+5$ & $3.80 \mathrm{E}+5$ & $3.74 \mathrm{E}+5$ & $3.61 \mathrm{E}+5$ & $3.67 \mathrm{E}+5$ \\
\hline HE340A & $6.83 \mathrm{E}+5$ & $4.96 \mathrm{E}+5$ & $5.03 \mathrm{E}+5$ & $4.42 \mathrm{E}+5$ & $4.44 \mathrm{E}+5$ & $4.25 \mathrm{E}+5$ & $4.20 \mathrm{E}+5$ & $4.17 \mathrm{E}+5$ \\
\hline
\end{tabular}

Table 2. Characteristics for European Rolled HEB-Sections in S355 Subject to Transverse Compression

\begin{tabular}{|c|c|c|c|c|c|c|c|c|}
\hline \multirow{2}{*}{$\begin{array}{l}\text { Section } \\
\text { type }\end{array}$} & \multicolumn{2}{|l|}{$\zeta=1 / 4$} & \multicolumn{2}{|l|}{$\zeta=3 / 8$} & \multicolumn{2}{|l|}{$\zeta=1 / 2$} & \multicolumn{2}{|l|}{$\zeta=5 / 8$} \\
\hline & $k_{c_{1+2}}[\mathbf{N} / \mathbf{m m}]$ & $F_{\mathrm{c}_{1+2}}[\mathrm{~N}]$ & $k_{c_{1+2}}[\mathbf{N} / \mathbf{m m}]$ & $F_{\varepsilon_{1+2}}[\mathrm{~N}]$ & $k_{c_{1+2}}[\mathbf{N} / \mathbf{m m}]$ & $F_{c_{1+2}}[\mathrm{~N}]$ & $k_{c_{1+2}}[\mathbf{N} / \mathbf{m m}]$ & $F_{\mathrm{c}_{1+2}}[\mathrm{~N}]$ \\
\hline HE200B & $12.63 \mathrm{E}+5$ & $4.79 \mathrm{E}+5$ & $8.58 \mathrm{E}+5$ & $4.04 \mathrm{E}+5$ & $7.36 \mathrm{E}+5$ & $3.81 \mathrm{E}+5$ & $6.89 \mathrm{E}+5$ & $3.72 \mathrm{E}+5$ \\
\hline HE220B & $11.84 \mathrm{E}+5$ & $5.18 \mathrm{E}+5$ & $8.16 \mathrm{E}+5$ & $4.43 \mathrm{E}+5$ & $7.03 \mathrm{E}+5$ & $4.19 \mathrm{E}+5$ & $6.59 \mathrm{E}+5$ & $4.10 \mathrm{E}+5$ \\
\hline HE260B & $11.19 \mathrm{E}+5$ & $6.00 \mathrm{E}+5$ & $7.86 \mathrm{E}+5$ & $5.21 \mathrm{E}+5$ & $6.81 \mathrm{E}+5$ & $4.96 \mathrm{E}+5$ & $6.40 \mathrm{E}+5$ & $4.86 \mathrm{E}+5$ \\
\hline HE280B & $10.19 \mathrm{E}+5$ & $6.19 \mathrm{E}+5$ & $7.22 \mathrm{E}+5$ & $5.40 \mathrm{E}+5$ & $6.27 \mathrm{E}+5$ & $5.14 \mathrm{E}+5$ & $5.89 \mathrm{E}+5$ & $5.03 \mathrm{E}+5$ \\
\hline HE300B & $10.01 \mathrm{E}+5$ & $6.63 \mathrm{E}+5$ & $7.29 \mathrm{E}+5$ & $5.89 \mathrm{E}+5$ & $6.42 \mathrm{E}+5$ & $5.67 \mathrm{E}+5$ & $6.08 \mathrm{E}+5$ & $5.57 \mathrm{E}+5$ \\
\hline HE320B & $12.06 \mathrm{E}+5$ & $7.71 \mathrm{E}+5$ & $8.72 \mathrm{E}+5$ & $6.85 \mathrm{E}+5$ & $7.65 \mathrm{E}+5$ & $6.59 \mathrm{E}+5$ & $7.23 \mathrm{E}+5$ & $6.48 \mathrm{E}+5$ \\
\hline HE400B & $17.55 \mathrm{E}+5$ & $10.27 \mathrm{E}+5$ & $12.54 \mathrm{E}+5$ & $9.24 \mathrm{E}+5$ & $10.88 \mathrm{E}+5$ & $8.90 \mathrm{E}+5$ & $10.23 \mathrm{E}+5$ & $8.78 \mathrm{E}+5$ \\
\hline
\end{tabular}

\section{Failure of Bolts in Compression}

Tensile loading is the most used loading mode of bolts. Possible failure of a bolt under axial tensile loading generally occurs in one of three modes: 1) tension failure through the shank or threaded section of the bolt, 2) stripping of the bolt threads, or 3) stripping of the nut threads. Thread stripping is a shear failure of an internal or external thread, which occurs either by stripping of the threads of the bolt or by stripping of the threads of the nut, depending on their relative strengths. The thread stripping strengths can be calculated according to Alexander's theory [18] with equations (5) (bolt thread stripping strength, $F_{S b}$ ) and (6) (nut thread stripping strength, $F_{S n}$ ). In general, bolts and nuts are designed so that tension failure of the bolt occurs before stripping of the threads. However, when subject to compressive loading, other failure behaviour might govern the strength of a bolt- nut assembly.To provide insight into the behaviour of bolts subject to compressive loading, experiments were carried out.

$F_{S b}=\frac{f_{y b}}{\sqrt{3}} A_{S b} C_{1} C_{2}$

where: $A_{S b}=\frac{\pi m^{*} D_{1}}{p}\left[\frac{p}{2}+\frac{1}{\sqrt{3}}\left(d_{2}-D_{1}\right)\right]$

$F_{S n}=\frac{f_{y n}}{\sqrt{3}} A_{S n} C_{1} C_{3}$

where: $A_{S n}=\frac{\pi m^{*} d}{p}\left[\frac{p}{2}+\frac{1}{\sqrt{3}}\left(d-D_{2}\right)\right]$

Where: 
$A_{S b}=$ bolt thread shear area $\left[\mathrm{mm}^{2}\right]$

$A_{S n}=$ nut thread shear area $\left[\mathrm{mm}^{2}\right]$

$C_{i}=$ strength reduction factor $[\mathrm{mm}]$

$m^{*}=$ effective nut height for stripping [mm] (for standard nuts $m^{*}=0.75 D$ )

$D_{1}=$ minor diameter of the nut thread [mm]

$D_{2}=$ pitch diameter of the nut thread [mm]

$d=$ major diameter of the bolt thread [mm]

$d_{2}=$ pitch diameter of the bolt thread [mm]

$p=$ pitch of the thread [mm]

High-strength M24 bolt-nut assemblies were tested by compressive loading in a compression test setup. The load was applied under controlled displacement conditions. For this purpose the loading plate was controlled at 0.10 $\mathrm{mm} / \mathrm{min}$. Deformations were measured with three linear variable differential transformers (LVDTs) equally divided around the circumference of the shank of the bolt. Based on these three measurements, the average deformation in the middle of the bolt could be derived. Additionally, it could be shown whether, besides to normal force, the bolt was subject to bending moment. The LVDT measuring distance applied was $50 \mathrm{~mm}$. For the fastening of the LVDTs to the bolt, a fixing medium was designed.

Regular bolt-nut combinations ( $\mathrm{RC}$ ), being nuts with a grade indication that matches the first number of the bolts with which they are used, as well as unusual combinations (UC) were tested in compression. The latter combinations were also dealt with in order to possibly find failure mechanisms with a large deformation capacity. A survey of the test program is provided in Table 3. All tests were carried out twice, indicated with the character A or B respectively at the end of the test code.

Table 3. Test Program for Component 'Bolts in Compression'

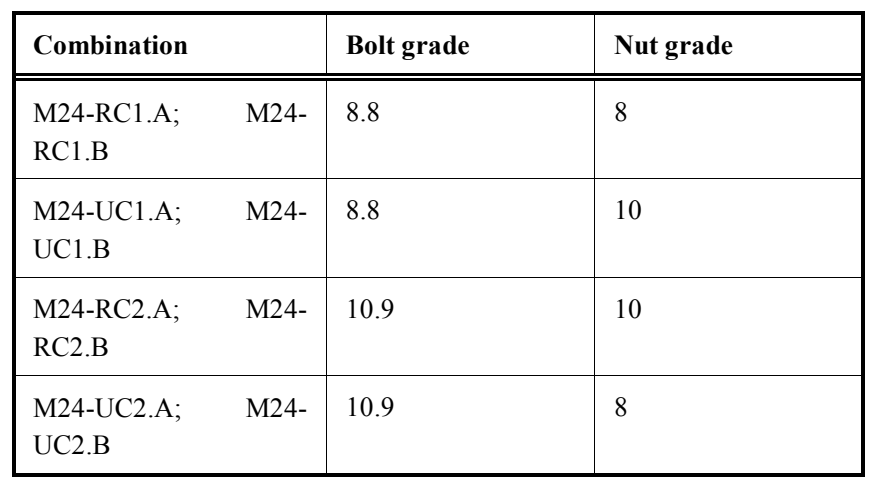

Tensile tests were performed on test coupons made out of bolts from the same series as used for the tests, to determine the actual material properties of the bolts. Table 4 gives the yield stress $f_{y b}$ (equivalent to the 0.2 proof stress for the 10.9 bolts) and the ultimate tensile stress $f_{u b}$ of the bolts applied.
Table 4. Bolt Material Properties

\begin{tabular}{|l|l|l|}
\hline Test coupon & $\left(f_{y b}\right)\left[\mathbf{N} / \mathbf{m m}^{2}\right]$ & $\left(f_{u b}\right)\left[\mathbf{N} / \mathbf{m m}^{2}\right]$ \\
\hline \hline $8.8 \mathrm{M} 24$ bolt & 571 & 768 \\
\hline $10.9 \mathrm{M} 24$ bolt & 1028 & 1112 \\
\hline
\end{tabular}

It is noticeable that the strength properties of the $8.8 \mathrm{M} 24$ bolt are lower than its nominal properties $\left(f_{y b}=640 \mathrm{~N} / \mathrm{mm}^{2}\right.$ and $f_{u b}=800 \mathrm{~N} / \mathrm{mm}^{2}$ ).

Fig. (10). presents the load-deformation diagrams of the M24 bolt-nut assemblies subject to compressive loading. The deformation shown is the calculated average deformation in the centre of the bolt. Furthermore, the analytical (yield) stripping strength $\left(F_{S y}\right)$ and ultimate stripping strength levels $\left(F_{S u}\right)$ are indicated. The analytical stripping strengths of all bolt-nut assemblies except UC2 are governed by bolt thread failure instead of nut thread failure.

The observed failure mode for all bolt-nut assemblies is stripping of the threads of the bolt (Fig. 11). In addition, for test series UC1, longitudinal and transverse plastic deformation of the threaded part of the bolt above the nut is also visible after the tests (Fig. 11b). For test series UC2, the threads of the nut have deformed plastically, although no stripping occurred (Fig. 11c). Considering deformation capacity, it is shown that the regular bolt-nut combinations possess almost an equal deformation capacity. The application of bolts of lower grades than the nuts results in more ductility (UC1). On the other hand, the combination of bolts with higher grades than the nuts provides less ductility (UC2). Therefore, the use of the latter combination is not to be recommended.

The average experimentally found failure loads are presented in Table 5 together with the bolt yield strength $\left(F_{B y}\right)$, the tensile strength $\left(F_{B u}\right)$ and the ultimate stripping strength $\left(F_{S u}\right)$ according to Alexander's theory. In the last column, a comparison is made between the analytically determined stripping strength and the experimental strength.

The results show that, unlike bolts subject to tensile loading, bolts subject to compressive loading fail by thread stripping failure and not by axial failure of the bolt, although some yielding of the bolt takes place (Fig. 11). Good agreement has been shown between the experimentally found ultimate strengths and the ultimate strength predictions according to Alexander's theory. Therefore, it has been concluded that this theory can be applied for the prediction of the stripping strength of bolt-nut assemblies subject to compressive loading.

\section{Plates in Compression}

When compressing a bolt to a steel plate, the stress state under the bolt is not a simple uni-axial state of stress. Experiments have been carried out to provide insight into the behaviour of steel plates subject to compression produced by bolts (Fig. 12). As the steel cap is loaded by a bolt that enters partly the hole in the cap, it is impracticable to measure deformations of the cap and plate only. Therefore, the load deformation characteristics of the component "plates in com- 

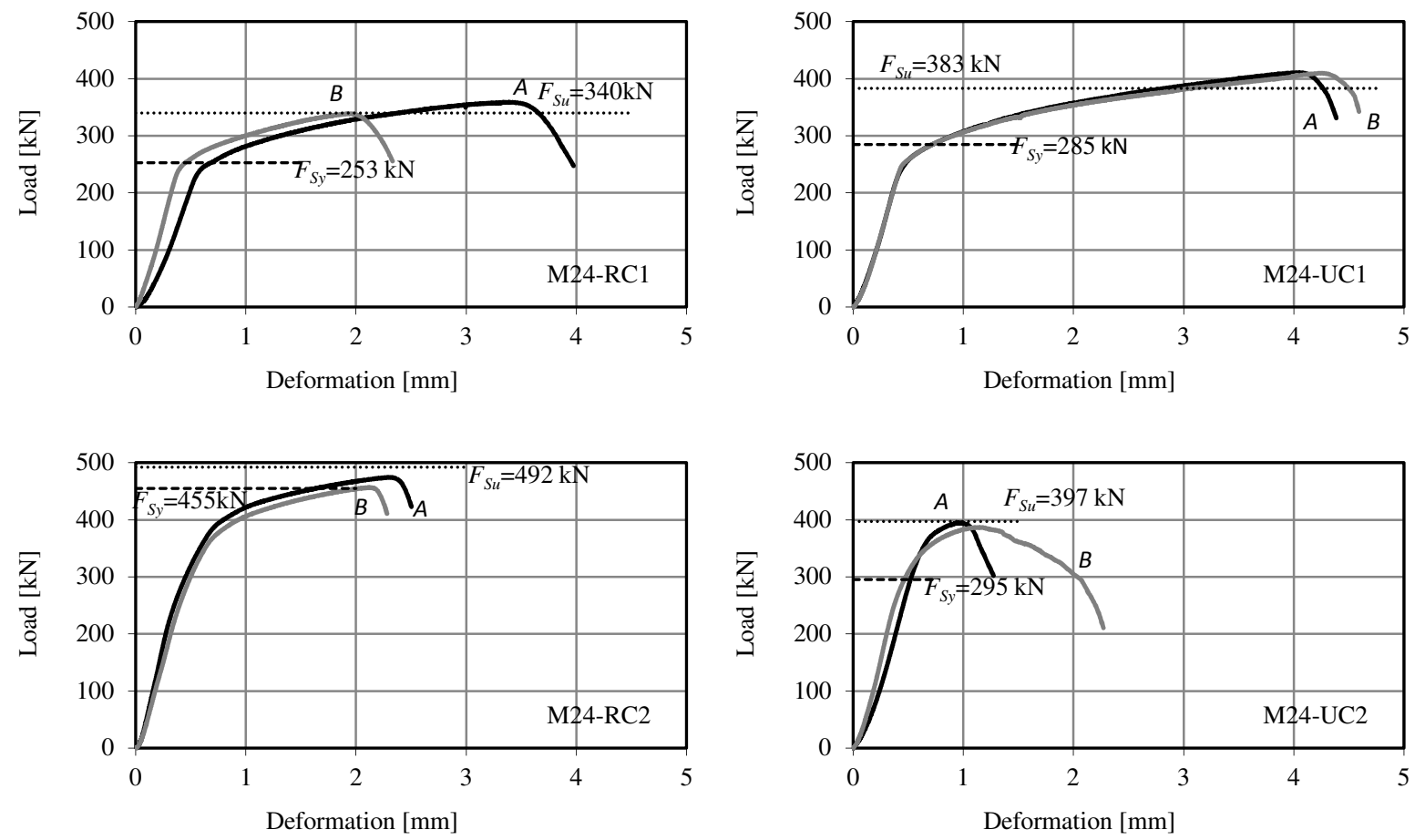

Fig. (10). Load-deformation response of bolt-nut assemblies subject to compressive loading.

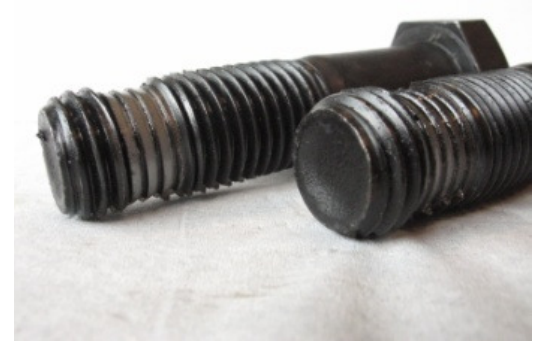

(a)

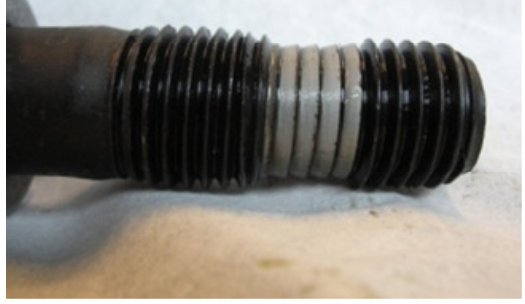

(b)

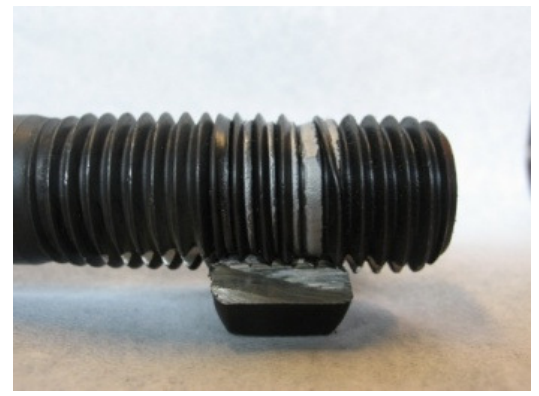

(c)

Fig. (11). Bolt thread stripping failure with some yielding of the threaded part (b) or the nut (c).

Table 5. Survey of Experimental and Analytical Results

\begin{tabular}{|l|l|l|l|l|l|}
\hline Combination & $\begin{array}{l}\text { Yield strength } \\
F_{B y}[\mathbf{k N}]\end{array}$ & $\begin{array}{l}\text { Tensile strength } \\
F_{B u}[\mathbf{k N}]\end{array}$ & $\begin{array}{l}\text { Stripping strength } \\
F_{S u} F_{S u}[\mathbf{k N}]\end{array}$ & $\begin{array}{l}\text { Experimental } \\
\text { strength }[\mathbf{k N ]}]\end{array}$ & Comparison \\
\hline \hline M24-RC1 & 202 & 271 & 340 & 349 & $-3 \%$ \\
\hline M24-UC1 & 202 & 271 & 383 & 410 & $-6 \%$ \\
\hline M24-RC2 & 363 & 393 & 492 & 465 & $+6 \%$ \\
\hline M24-UC2 & 363 & 393 & 397 & 391 & $+2 \%$ \\
\hline
\end{tabular}

pression' are obtained in combination with the component 'bolt in compression'. The load is applied under controlled displacement conditions. For this purpose the loading plate is displaced at $0.10 \mathrm{~mm} / \mathrm{min}$. Three LVDTs equally divided around the bolt are used to measure the deformation of the bolt, cap and plate. The length of the bolt-nut assembly including the cap and plate is $65 \mathrm{~mm}$.

Fig. (13) shows the load-deformation characteristics of tests. It was shown by the experiments that bolt failure gov- erns the strength. The results of the tests allowed determination of the linear elastic stiffness for the combined components 'plates in compression' and 'bolt in compression': $k_{c 3+4}$ $=6,0 \mathrm{E}+5 \mathrm{~N} / \mathrm{mm}$.

\section{Discrete Panel-to-Frame Connection Stiffness}

The initial panel-to-frame connection stiffness $\left(k_{c ; \text {;ini }}\right)$ can be composed of the stiffness obtained from the component experiment 'bolt with cap on plate in compression' (Fig. 13) 

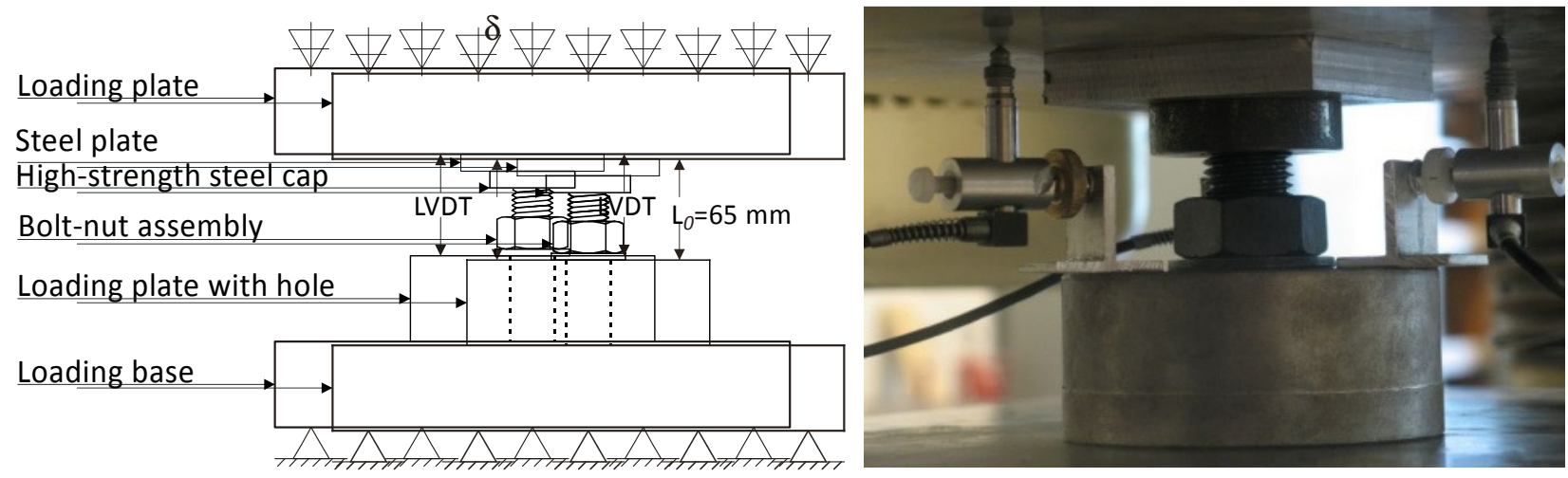

Fig. (12). Test setup for component plates in compression.

in combination with the results from the finite element Fig. (15a), in Tables $\mathbf{1}$ and $\mathbf{2}$ as follows:

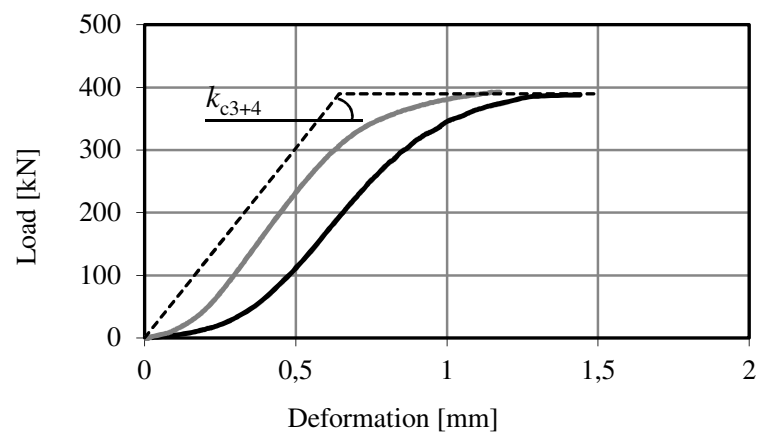

Fig. (13). Load-deformation response of compression tests on bolt with cap on plate, with bilinear approximation.

$k_{c ; i n i}=\left[\frac{1}{k_{c_{1+2}}}+\frac{1}{2 k_{c_{3+4}}}\right]^{-1}$

The factor 2 in the equation accounts for two bolts found in one panel-to-frame connection.

\section{Example:}

A discrete panel-to-frame connection with HE360B sections and $8.8 \mathrm{M} 24$ bolts, where for the position of the bolts with respect to the end plate holds $\zeta=1 / 4$ :

- $k_{c l+2}=15.08 \mathrm{E}+5 \mathrm{~N} / \mathrm{mm}$ (Table 2)

- $F_{c l+2}=9.20 \mathrm{E}+5 \mathrm{~N}$ (Table 2$)$

- $k_{c 3+4}=6.0 \mathrm{E}+5 \mathrm{~N} / \mathrm{mm}$ (Fig. 13)

- $F_{c 3+4}=2 \times 253=506 \mathrm{kN}$ (Analytical strippingyielding strength $F_{S y}$ for 2 bolts, Fig. 10)

- $F_{c 3+4}=2 \times 340=680 \mathrm{kN}$ (Analytical stripping ultimate strength $F_{S u}$ for 2 bolts, Fig. 10)

$k_{c: \text { ini }}=\left[\frac{1}{k_{c_{1+2}}}+\frac{1}{2 k_{c_{3+4}}}\right]^{-1}=\left[\frac{1}{15.08 \mathrm{E}+5}+\frac{1}{2 \times 6.0 \mathrm{E}+5}\right]^{-1}=6.7 \mathrm{E}+5 \mathrm{~N} / \mathrm{mm}$

$F_{c}=\min \left[F_{c_{1+2}}, F_{c_{3+4}}\right]=680 \mathrm{kN}$

Combined, this gives the load-deformation response presented in Fig. (14), approximated by elastic-ideal plastic behaviour where the level of the plastic branch is defined by the bolt stripping strength. The post-yielding stiffness is taken as zero, which means that strain hardening and geo- metric nonlinear effects are neglected. The limit displacement equals $2,5 \mathrm{~mm}$, matching the component test results. The dashed line gives the load-deformation response composed of the measured and simulated results.

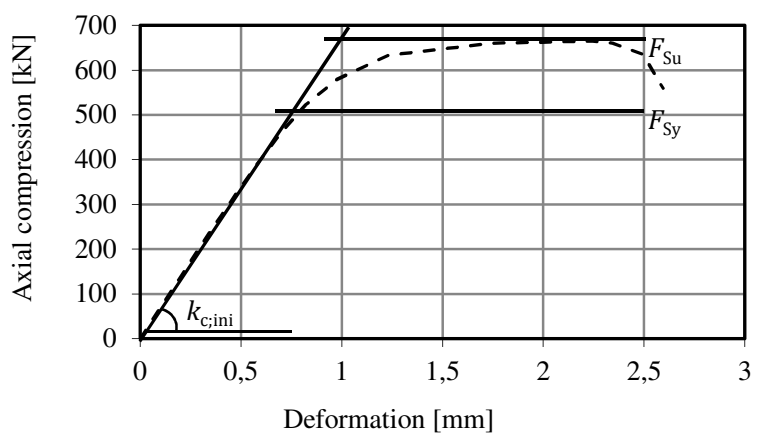

Fig. (14). Load-deformation response for discrete panel-to-frame connection with HE360B sections and 8.8M24 bolts.

\section{Structural Characteristicsof Precast Concrete Panel with Window Opening}

As the infilled frame structure is developed to be applied in a building's facade, window openings in the panels are inevitable. In this study, central panel openings are considered. From a practical and structural point of view this is the best location to accommodate window openings [6]. By application of the discrete panel-to-frame connection considered, the infill panel has to act as a diagonal strut in compression. However, a central panel opening will interrupt the development of a main compression strut.

The load distribution in a panel with central window opening can be obtained by developing a strut-and-tie model (STM). As the development of a main compression strut is interrupted, the load is transferred around the opening. This results in tensile forces in the outer edge of the panel which have to be resisted by appropriate reinforcement. Fig. (15a) shows the positions of the main concrete struts and tensile ties as well as two other short concrete struts, which are necessary to maintain equilibrium. The adopted strut-and-tie model can be considered as two knee frames, pin connected to each other in the loaded corners. These corners are, according to the adopted strut-and-tie model, unable to support bending forces. Therefore, this stress field will cause considerable deformations, concentrated in open cracks. In order to avoid these considerable concentrated deformations, addi- 


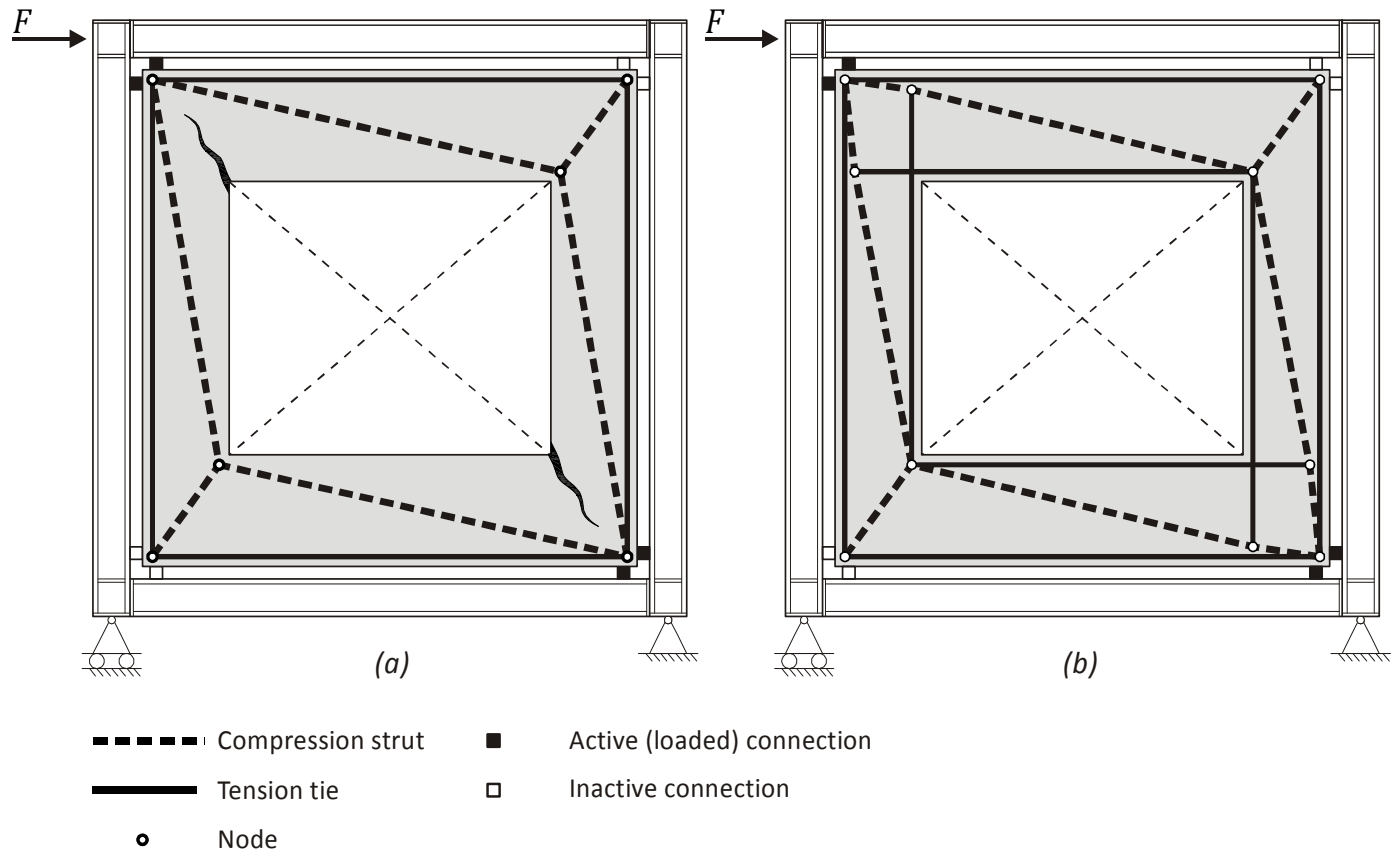

Fig. (15). Development of STM for laterally loaded infilled frame with central panel opening:possible STM with considerable deformations (a) andSTM with additional reinforcementaround the inner edge (b).

tional reinforcement is required around the inner edge of the panel to support tensile forces there. This results in the strutand-tie model shown in Fig. (15b).

This strut-and-tie model can be applied to determine the required amount of reinforcement, to provide the demanded strength $\left(F_{p}\right)$ of infill panels with window openings. As well, the struts and nodes of the strut-and-tie model, including those located at the load introduction by the bolts, shall be designed for sufficient load bearing resistance. However, a simple method to establish the panel stiffness $\left(k_{p}\right)$ does not exist yet. Therefore the size and vertical position of the panel opening have been experimentally investigated. Full scale tests were performed on infilled frames with five different window opening geometries. An elaborated description of the full scale tests can be found in Teeuwen et al. [9]. Finite element models, simulating the response of the tested semiintegral infilled frames with window openings are discussed in Teeuwen et al. [19, 20].

\section{CONCLUSIONS}

A mechanical model has been proposed for the semiintegral infilled frame with discrete panel-to-frame connections comprising of structural bolts acting under compression. The model is based on the concept of the equivalent diagonal strut and the panel-to-frame connections are modelled as four serial springs. This mechanical model enables analysing a building structure consisting of semi-integral infilled frames by standard structural analysis methods. Input for the model are geometrical and material properties of the frame structure and the structural characteristics of springs representing the frame joints, panel-to-frame connections and the infill panel respectively.

Structural characteristics of the discrete panel-to-frame connection were obtained from experiments on individual connection components. Tables have been developed with numerical simulations to determine the elastic stiffness and strength of flanges of HEA and HEB sections in bending, as function of the distance from the bolt to the endplate.

Unlike bolts subject to tensile loading, bolts subject to compressive loading fail by thread stripping and not by yielding of the bolt. The use of bolts with lower grades than the nuts results in more ductile behaviour while for the bolt combined with nuts with lower strength less ductility occurs. Applicability of Alexander's theory for bolt-nut assemblies subject to compression has successfully been validated.

The results of the research allow estimating the structural characteristics of the considered discrete panel-to-frame connection for different frame sections.

\section{CONFLICT OF INTEREST}

The authors confirm that this article content has no conflicts of interest.

\section{ACKNOWLEDGEMENT}

Declared none.

\section{REFERENCES}

[1] M. Holmes, "Steel frames with brickwork and concrete infilling", Proc. Inst. Civil Eng., vol. 19, pp. 473-478, 1961.

[2] B. M. Ng'andu, "Bracing Steel Frames With Calcium Silicate Element Walls”, Ph.D. Dissertation, Eindhoven University of Technology, Netherlands, 2006.

[3] P.G. Asteris, "Lateral stiffness of brick masonry infilled plane frames", J. Struct. Div. ASCE, vol. 129, no. 8, pp. 1071-1079, 2003.

[4] A. Mohebkhah, A.A. Tasnimi, and H.A. Moghadam, "Nonlinear analysis of masonry-infilled steel frames with openings using discrete element method", J. Constr. Steel Res., vol. 64, no. 12, pp. 1463-1472, 2008.

[5] P.G. Asteris, D.J. Kakaletsis, C.Z.Chrysostomou, and E.E. Smyrou, "Failure modes of infilled frames, Electron. J. Struct. Eng., vol. 11, no. 1, pp.11-20, 2011. 
[6] J. L. Dawe, and C.K. Seah, "Behaviour of masonry infilled steel frames", Can. J. Civil Eng., vol. 16, no. 6, pp. 865-876, 1989.

[7] R. J. Frosch, "Seismic Rehabilitation Using Precast Infill Walls", Ph.D. Dissertation, University of Texas, Austin, 1996.

[8] R.B. Tang, J.C.D. Hoenderkamp, and H.H. Snijder, "Preliminary numerical research on steel frames with precast reinforced concrete infill panels", Proceedings of the 1st Conference on Structural Stability and Dynamics, Taipei, 2003, pp. 575-580.

[9] P.A. Teeuwen, C.S. Kleinman, H.H. Snijder, and H. Hofmeyer, "Full-scale testing of infilled steel frames with precast concrete panels provided with a window opening", Heron, vol. 53, no. 4, pp. 195-223, 2008.

[10] J.C.D. Hoenderkamp, H. Hofmeyer, and H.H. Snijder, "Experimental investigation of the shear resistance of steel frames with precast concrete infill panels", Adv. Steel Constr., vol. 6, no. 3, pp. 817830, 2010.

[11] S.V. Polyakov, "On the interaction between masonry filler walls and enclosing frame when loaded in the plane of the wall", Translation in Earthquake Eng., Earthquake Engineering Research Institute: San Francisco, pp 36-42, 1956.

[12] J. Witteveen, J.W.B. Stark, F.S.K. Bijlaard, and P. Zoetemeijer, "Welded and bolted beam-to-column connections", J. Struct. Div. $A S C E$, vol. 108, no. 2, pp. 433-455,1982.
[13] J.W.B. Stark, and F.S.K. Bijlaard, "Design rules for beam-tocolumn connections in Europe", J. Constr. Steel Res., vol. 10, pp. 415-462, 1988.

[14] EN 1993-1-8, Eurocode 3: Design of steel structures - Part 1-8: Design of joints, CEN, Brussels, 2005.

[15] EN 1993-1-5, Eurocode 3: Design of steel structures - Part 1-5: General rules - Plated structural elements, CEN, Brussels, 2006.

[16] P. Zoetemeijer, "A design method for the tension side of statically loaded, bolted beam-to-column connections", Heron, vol. 20, no. 1, pp. 1-59, 1974.

[17] C.M. Steenhuis, A.C.W.M. Vrouwenvelder, F. van Herwijnen, and H.H. Snijder, "Definitions of resistance and deformation capacity for non-sway steel and composite structures", Heron, vol. 47, no. 1, pp. 3-27, 2002.

[18] E.M. Alexander, "Analysis and design of threaded assemblies", SAE Papers, vol. 770420, pp. 1-15, 1977.

[19] P.A. Teeuwen, C.S. Kleinman, H.H. Snijder, and H. Hofmeyer, "Experimental and numerical investigations into the composite behaviour of steel frames and precast concrete infill panels with window openings", Steel Compos. Struct., vol. 10, no. 1, pp. 1-21, 2010.

[20] P.A. Teeuwen, Lateral behavior of steel frames with discretely connected precast concrete infill panels, XVI. Eindhoven University Press: Eindhoven 2009, p. 195.

(C) Teeuwen et al.; Licensee Bentham Open.

This is an open access article licensed under the terms of the Creative Commons Attribution Non-Commercial License (http://creativecommons.org/licenses/by-nc/3.0/) which permits unrestricted, non-commercial use, distribution and reproduction in any medium, provided the work is properly cited. 